\title{
Empowerment through Residence
}

\author{
PETER SOMERVILLE
}

[ABSTRACT What does it mean to empower people through the housing in which they live, and how is this empowerment to be achieved? These are the questions which are examined in this paper. Typologies of empowerment processes are devised in an attempt to make sense of the conceptual and empirical variety involved. The distinction between 'top-down' and 'bottom-up' empowerment orientations is argued to be particularly important for understanding the content, pattern and general direction of empowerment processes. Empowerments through knowledge, statute, resources, agreement and speci® $c$ power transfer are then discussed in relation to speci® $c$ housing contexts, in particular the context of social housing management. The utility of the typologies of empowerment processes is tested in application to speci® $c$ tenant participation arrangements. It is concluded that resident empowerment is worth pursuing not only for its own sake, but for the bene ${ }^{\circledR}$ ts which it can bring to a wider society.

\section{The Meaning of Empowerment}

The concept of power has been strongly contested since Lukes (1974). As an abstract general concept, it has suffered from a high degree of vagueness and ambiguity, which has severely limited its theoretical utility (Barnes, 1988; Clegg, 1989). As a practical concept, however, it remains extremely popular, because of its emotive content, and consequently plays a major role in political debate and policy making.

The concept of empowerment is generally intended in the more practical sense, as involving a process by which people who are disadvantaged or excluded acquire something of the character of citizens (Harrison, 1995, p. 22). At the same time, however, the concept of empowerment retains a necessary element of vagueness, associated with the abstract general meaning of power, from which it is derived.

It is possible, therefore, that the concept of empowerment is not amenable to a precise general definition. Provisionally, however, it is suggested that empowerment could be described as any process by which people's control over their lives is increased. The exact meaning of increasing control can then be spelled out only in specific contexts such as employment, housing or education, although the general theme in each of these contexts will be one of increasing choice and freedom of action for the people affected.

\section{Empowerment in a Housing Context}

This paper is concerned speciß cally with housing-related empowerment, and this can be defined as any process by which people gain increased control over their housing situation. Such control can be individual or collective, over production or consumption, over investment or management. The paper is concerned mainly with collective control over housing consumption and management, but this should not be taken to imply any collectivist, consumptionist or managerial bias in the treatment of housing empowerment. It should also be noted from the outset that it may not be possible to draw any precise distinction between a process which gives people more control over their housing and one which gives them more control over their residential environment (encompassing roads, schools, shops, parks, leisure centres, and so on, and including the regulation of behaviour within that environment).

The paper starts by distinguishing empowerment from participation, and makes a number of comments relating to the recent literature on tenant participation in particular. It is argued that there is a need for a more rigorous examination of empowerment processes, and in the following section an attempt is made to devise a typology of such processes which is completely different from any typology of tenant participation processes. This typology is then applied in the following sector to important recent developments in Britain which have involved, or have been claimed to involve, the empowerment of residents. Specific means of empowerment which are considered include the provision of information, the passing of legislation, the commitment of resources, and the transfer of management functions. The ${ }^{\circledR}$ nal section of the paper then brie ${ }^{-} y$ discusses the implications of the arguments on empowerment for the development of communities and the changing role of housing management.

As Harrison (1995, p. 22) points out, "empowerment clearly means more than ... participation", but it may be worth considering just how much more 
empowerment does involve. People may participate individually or collectively in an activity without thereby experiencing any increase in their control over their lives. This can happen if those who control that activity simply want to use the participation for their own ends. For example, they may want to make themselves better informed on a subject of which the participants have special knowledge, or they may merely want to go through the motions of participation without taking seriously the participants' contributions. They may want to promote an image of themselves as "listening to the people" but without any real commitment to the empowerment of those people. Participation without empowerment is therefore a confidence trick performed by the controllers of an activity on participants in that activity. To the extent to which the trick works, it must be disempowering rather than empowering. Those who take this cynical approach, however, should bear in mind the arguments of Foucault (1980), to the effect that simply entering into discussion about what can or cannot be done is itself an empowering process, so that those who initiate participation, even with disempowering intent, may ${ }^{\circledR}$ nd themselves forced or influenced to act in ways which they had not originally intended.

Bearing in mind the above caveat, there is in fact a good deal of overlap between participation and empowerment. For example, mechanisms for consultation clearly involve the participation of those consulted, but the participants are also empowered to the extent to which attention is paid to their views and concerns. This argument is obviously stronger with regard to the forms of participation where participants can hold decision makers to account for what they do and where participants have some say in the decision making process itself. In these cases, the specificity of participation is practically de $\AA$ ned by the nature of the empowerment which it creates.

It is not the purpose of this paper to conduct a detailed review of the literature on empowerment and resident control. However, it may be worth repeating some of the main findings of that literature. Various researchers over the years have concluded that resident-controlled housing is both more efficient (Turner, 1982, p. 109) and more effective (Ward, 1976), but this has not been generally recognised by housing organisations and housing professionals until relatively recently. This could be in part because most of the literature is concerned with housing provision rather than housing use or management (which is the focus of this paper), a bias which is ironically even more pronounced in more recent writings (Mathe'y, 1992). It should be noted only in passing, therefore, that there is a growing literature on empowerment more generally (that is, beyond housing), and this literature tends to concentrate on issues of individual psychology rather than collective action, although it is recognised that there is a reciprocal relationship between psychological empowerment and community involvement and participation (Zimmerman \& Rappaport, 1988). On the whole, with one or two notable exceptions (for example, Cairncross et al., 1994), the debate has not really gone beyond a consideration of what Harrison (1995) calls "therapeutic strategies" (p. 23), that is professional, or possibly self-help, practices directed at improving the quality of life for disadvantaged citizens.

Cairncross et al. (1994) posed the question directly of whether tenant participation empowered the tenants concerned, and their answer was that "it all depends" (p. 198). Basically, there were two types of strategy for empowering themselves which participating tenants could deploy: working within the rules of the game set by their landlord, or contesting those rules by questioning the landlord's definition of permissible participation and creating new points at which landlord and tenants could formally interact (Cairncross et al., 1994, p. 180) (such points were held by Clegg, 1989, to be particularly significant for power relations). Tenants' groups who followed the latter type of strategy, however, were likely to have their legitimacy questioned by their landlord who would then use this to justify their marginalisation and exclusion (Cairncross et al., 1994, p. 190). Fortunately for tenant empowerment, then, the structure and processes of tenant participation offer a rich variety of opportunities for tenants to gain advantage even while ostensibly playing by the landlord's rules. I have discussed certain aspects of the relation between tenant participation and empowerment elsewhere (Somerville \& Steele, 1995a). There it was argued that increasing participation alone cannot achieve the lasting empowerment of the participants. What is needed in addition are institutional arrangements for informing, training and educating those participants, and for securing a permanent shift in the balance of power from landlord to tenants. The paper suggested that tenant empowerment is only one of three criteria by which tenant participation can be assessed (the others being effectiveness and representativeness), and 
three different types of institutional arrangement for tenant participation were outlined, namely internal markets, tenant-led management, and landlord-tenant partnerships. It was concluded that tenant empowerment was potentially lowest under internal market arrangements (although still higher than under many current bureaucratic arrangements), and highest under systems of tenant control; landlord-tenant partnerships, such as those based on estate agreements (Steele et al., 1995), tended to be more empowering of tenants than internal markets, but obviously less empowering than full tenant control. Arrangements which are potentially more empowering for tenants, however, may have disadvantages in other respects. For example, they may incur burdens of responsibility, or they may empower only a minority of tenants who may not be suf® ciently representative of the tenants as a whole or who may lack the necessary skills or commitment. The key goal for empowerment is that people should be in a position where they can freely choose the type of participation arrangement into which they wish to enter, and what they need to achieve this is "the right blend of external support, democratic selection and civic education" (Somerville \& Steele, 1995a, p. 278). This paper explores a little of what is involved in such a blend.

Stewart \& Taylor (1995) have recently made an important contribution to the literature on empowerment in a housing context. They argue that empowerment can be understood in terms of four 'dimensions' (which have nothing in common with those of Lukes, 1974): process, degree, focus and ownership (Stewart \& Taylor, 1995, p. 13). The basis for this typology, however, is not explained or justified, and therefore alternative typologies are possible. They also argue that "empowerment has to be seen as a cycle" (p. 18), and in their conclusion they describe what they call "a cycle of disempowerment" (p. 66), according to which disempowerment flows through structures of exclusion, isolation, dependency and marginalisation. The ontological status of these structures (or 'levels', as they call them), however, is not clear. They may perhaps be processes, but if they are really structures we need to know what sort of structures they are, how they bring about the effects they do, how they relate to the dimensions outlined at the beginning, and how they ${ }^{\circledR} \mathrm{t}$ in with the theoretical literature on power (Lukes, Clegg, etc). For these reasons, it would appear that Stewart \& Taylor 's analysis needs to be developed further and with greater rigour, and this task is attempted in the next section.

Finally, empowerment needs to be distinguished from sustainable development with which it overlaps (Dwelly, 1996; Fordham, 1995). Essentially, sustainability is about ensuring that the consumption of resources by the current generation does not occur at the expense of the next generation. It can be argued that those living in an area are those who are most concerned for the future of the children in that area. If this is correct, then it follows that the empowerment of residents in that area will be most conducive to its sustainable development, and that improvements in the area, including such things as resident participation, are unlikely to be sustainable without such empowerment.

\section{Typologies of Empowerment Processes}

If we think of empowerment primarily as a process, then it is possible to classify such processes in a number of different ways. A useful starting point here is Stewart \& Taylor 's two-dimensional model of empowerment processes, which is reproduced in Figure 1 (Stewart \& Taylor, 1995, p. 15). Essentially, this model interprets empowerment in terms of the strategic options available to individuals or groups of people in dealing with powerful organisations. The ${ }^{\circledR}$ rst dimension of the model indicates that people can exercise active options such as voice and exit, or passive options such as loyalty or alienation. The second dimension, by contrast, sets out options as either constructive, like voice or loyalty, or destructive, like exit or alienation.

Figure 1. Process of empowerment. Note: Individual responses are shown in the diamond; collective responses are shown outside the diamond. Source: Stewart \& Taylor (1995).

This is an interesting model, but it has its problems. It is difficult to see, for example, how alienation can be represented as a process of empowerment: rather, it looks like disempowerment. This thought then raises the question of what exactly is the nature of the empowerment involved in each strategic option. For the exit option, for example, it could be argued that empowerment results not so much from the actual exercise of the option as from being given the power so to do it. This is because the reality of exit could be destructive and therefore disempowering for the people who follow this route, whereas the potential to exit can in some situations be used as a weapon to achieve 
improvements in their living or working conditions. Again, in the case of the loyalty option, it is difficult to see how such a passive strategy can involve empowerment, but on the other hand it is not necessarily disempowering either: it all depends on the nature of the relationship with the organisation to which loyalty is being pledged. Finally, even the exercise of the voice option is not a straightforward empowering process, because, as mentioned in the previous section, participation in itself does not necessarily change anything (Foucault notwithstanding). The link between the model and the reality of empowerment processes therefore appears tenuous.

Table 1. A classification of empowerment processes

Classificatory criteria Empowerment process

I Direction of action Top-down Bottom-up

II Dependency effect Increasing dependence Increasing independence

III Institutional change Conservative Radical Reformist

IV Beneficiaries Individuals Collectives Elites

In order to develop improved typologies of empowerment processes, it is

necessary to look behind the model of voice/exit/loyalty/alienation and consider

how the people-organisation relation is structured and how it is changing

through time. Such a consideration suggests that empowerment processes can

be classified according to the source of empowerment activity (those with power or those without power), the change in dependency relations between the two parties (increased dependence or increased independence), and the general effect on the organisations and institutions involved (conserving, restructuring or fragmenting). Stewart \& Taylor 's model applies only to the last of these classificatory criteria, and even then only in a modified form. In addition, the concerns

which Stewart \& Taylor have with the focus and ownership of empowerment could be covered by means of a classification in terms of the population which is the recipient or beneficiary of the empowerment flows (in general terms, selected individuals or groups of people, in a variety of roles) (see Table 1). In the case of the first classification criterion, namely that of the source of empowerment, the process of empowerment can either originate from those who have the power and move towards those who are to be empowered, or it can start with those seeking to be empowered and move towards those who already have the power. Empowerment processes of the former orientation can be described as moving in a 'top-down' direction, while those of the latter orientation can be labelled as 'bottom-up' processes. This is an important distinction, which has been prefigured in Turner 's (1990) distinction between citizenship developed from above (so-called 'passive' citizenship) and that developed from below ('active' citizenship). In practice, it is often assumed that empowerment is led from the top, as in so-called 'top-down' approaches to the analysis of policy implementation (Sabatier, 1986). In the case of Stewart \& Taylor (1995), however, as pointed out above, empowerment is characterised in terms of fundamental strategic choices made at the 'bottom' (although such choices are perhaps enabled and shaped by decisions made at the 'top'?).

Second, power can flow in such a way as either to increase the independence of those affected, or to make them more dependent on others, or to leave dependency relations more or less unchanged. There is a tendency to assume that empowerment must involve increasing independence, but this is not the case (for example, partnerships between organisations will increase their dependence upon each other but may also at the same time widen their overall sphere of action and influence). The assumption arises because empowerment is identified with enabling while dependence is commonly (and wrongly) associated with impairment, and impairment is in turn assumed to be disempowering (which it often is but does not have to be). The reality is that we are all interdependent, but some are more interdependent than others, and the degree of interdependence is not necessarily related to the capacity for reciprocity (which is a function of the power that can be exercised in the context of interdependence). This point is explained further below.

Third, there is an issue concerning whether empowerment involves deregulation or improved regulation. Both can be liberating, but in quite different ways. For example, for housing tenants, the goal could be that of freedom from landlords (which would of course mean the end of rented housing), expressed through exercise of the exit option, or it could be a more equal partnership with their landlord and with landlords generally (involving mutual dependency), achieved through the voice option. Alternatively, tenants may not seek to change their power relation with their landlord at all, but only to receive better services from that landlord, which may have the effect of empowering them in other ways (for example, an improved repairs service may save the tenant time and 
trouble which can then be devoted to more productive activities). Such tenants, whether they know it or not, are exercising the loyalty option. All three goals therefore involve empowerment, but the institutional outcomes are completely different. Empowerment processes can therefore be characterised as 'conservative', in the sense that they tend to conserve, and possibly enhance and expand, existing institutional structures, or 'radical', in the sense that they tend to break up existing institutional structures and create separate new power bases, untrammelled by the old systems of regulation, or they could be 'egalitarian' or 'reformist', in the sense that they tend to reform existing institutions into structures within which power is more equally distributed. In the case of radical empowerment, if the new power bases were actually to supplant the old ones, the effect could be described as 'revolutionary' change.

The distinction between 'conservative', 'reformist' and 'radical' empowerment cuts across the other two distinctions, between 'top-down' and 'bottom-up' empowerment orientations and between increasing and decreasing dependency effects. For example, the right to manage conferred on council tenants by the Leasehold Reform, Housing and Urban Development Act 1993 is a 'radical' empowerment measure because it enables tenants to free themselves from local authority managerial control, and it is 'top-down' empowerment because the initiative was driven entirely by central government with little support or even interest from tenants themselves. As for dependency effects, it might seem that the exercise of the right to manage by a tenants' group would increase the independence of that group because it would no longer have to rely on the local authority. In practice, however, the independence of the new tenant management organisation could prove illusory, as it would continue to be dependent on other organisations, especially for funding, and these organisations would include, inevitably, the local authority itself.

A final way to classify empowerment processes is in terms of the intended or actual recipients or beneficiaries of empowerment flows, and in particular whether they empower separate individual persons and elites, or broad collectivities and the mass of people generally. This is primarily an issue of the ownership of the empowerment which takes place, although in practice ownership is inseparable from the specific content of the empowering mechanisms (which Stewart \& Taylor call the 'focus' of empowerment-Stewart \& Taylor, 1995 p. 17). An estate agreement, for example, could be jointly owned by the collectivity of estate residents and estate office staff, and this joint ownership would be inextricable from the specific focus of the agreement on standards for housing service delivery and priorities for dealing with the estate's problems. On the other hand, however, the agreement might be seen as being owned by the housing organisation or its intermediaries, with the result that the agreement differs little from an orthodox individual tenancy agreement (Steele et al., 1995). Alternatively, it is possible that the agreement might be seen as owned by an elite group of tenants, so that the focus of the agreement is partial and insufficiently inclusive. There are some rights, such as the Right to Buy, whose exercise leads to the empowerment only of individuals. In terms of the distinctions drawn above, the Right to Buy is a 'top-down' 'radical' policy which creates independence to the extent that the purchasers become responsible for the maintenance and management, and possible improvement, of their own home, and are no longer dependent on a landlord for the provision of such services. The 'radical' nature of the policy can be clearly grasped from the fact that the Right to Buy is a right not just to exit from landlord control but to take one's residence with one, thereby undermining, if only slightly, the landlord's asset base.

Empowerment processes can be further distinguished according to their spatial focus or level of operation, for example empowerment at the level of a neighbourhood or housing estate, empowerment at the level of a local authority area, or empowerment at a national level. In practice, however, these different levels are intertwined in complex ways, and some illustrations of this are discussed below. Discussion of empowerment has in recent years been unnecessarily complicated by the introduction of terms such as 'social exclusion' and 'underclass'. As Room has pointed out, notions of social exclusion derive from conservative types of welfare regime (Room, 1995, p. 106), and indeed strategies of social inclusion can be identified with the conservative processes of empowerment referred to above. In contrast, strategies for equality in power and resources which derive from social democratic welfare regimes can be identified with reformist or egalitarian empowerment processes. Interestingly, the classification in Table 1 differs from Room's only with regard to so-called 'radical' empowerment processes. Whereas Room sees only a minor redistribution of resources in 
order to enable the poor to compete in the market (deriving from so-called liberal welfare regimes), this paper suggests strategies of increasing choice which may have either reactionary or revolutionary effects depending upon the context in which such choice is exercised. This argument indicates that the notion of a liberal welfare regime is too simplistic. In addition, the argument about social exclusion casts doubt on the meaning of exclusion as a 'level of disempowerment' as stated by Stewart \& Taylor (1995, p. 64), except perhaps as a means of justifying an essentially conservative strategy of social inclusion. The very concept of a cycle of disempowerment has to be treated with caution, because it is inextricably tied to what is ultimately a conservative political programme.

\section{Some Applications of Empowerment Typologies}

So far, the argument has been conducted at a fairly abstract level. The typologies developed above now need to be tested in relation to real housing policy processes. This paper concentrates primarily on issues of tenant participation. Ultimately, the aim is to show how an empowerment-focused approach can provide a means for the evaluation of housing and housing-related policy which will be of bene ${ }^{\circ} t$ to all.

Provisionally, for the purposes of evaluation, 'top-down' processes of empowerment can be analysed under four headings: (1) the communication of appropriate information, training and education; (2) the conferral of specific individual and collective rights; (3) the provision of appropriate financial and other resources; and (4) the transfer or recognition of specific powers of negotiation, decision-making and monitoring. Similarly, 'bottom-up' processes of empowerment fall into four main types: (1) increasing informal and formal participation in collective activity; (2) increasing exercise of rights conferred through 'top-down' processes; (3) increasing assertiveness in access to resources required for participation and for the exercise of conferred rights; and (4) increasing pressure for participation in decision-making processes. In this section, some examples are considered of these types of empowerment processes. It should be noted that in each case what is occurring is a specific flow of power or influence to tenants, either as individuals or as members of specific groups (or in specific official positions) or as tenants in general. The main difference between 'top-down' and 'bottom-up' processes is simply that in the former case the flow of power is initiated by the landlord, while in the latter case it is activated by the tenants. It is important to realise that this does not mean in either case that the power is actually ${ }^{-}$owing from the landlord, although this may well be happening in some situations (for example, with regard to the resourcing of tenants' organisations). Instead, it could be the result of growing co-operation and understanding between landlord and tenant, which work to the bene $\AA$ t of both parties: mutual growth enhances the power of the partnership between them, and thereby increases their power both jointly and separately. In this section, each of the provisional headings for 'top-down' or 'bottom-up' actions is used as means for structuring the discussion of resident empowerment processes. The classification of methods of empowerment under the various headings (knowledge acquisition, statute, resourcing, agreement and power transfer) is for convenience only, and is not intended to have any theoretical significance. The material discussed under each heading is then evaluated by reference to the typologies outlined in the previous section, and conclusions drawn wherever appropriate. As has been noted by Sabatier $(1986)$ and others, 'top-down' processes tend to predominate over 'bottom-up ones, but this is no more than one would expect in 'normal' (that is, non-revolutionary) situations. Empowerment through Knowledge

Considering the eight headings listed above, the first issue concerns what is to count as appropriate information for the purposes of empowerment. 'Knowledge is power', so the cliche goes, but in reality much depends upon the nature of the knowledge and how it is communicated. For example, owner occupiers may enjoy property rights over their home which empower them to a significant degree, but they may lack reliable information about the operation of the housing market and the practices of mortgage lenders, and this can leave them to some extent at the mercy of the housing market professionals and of the housing market itself (ending up, if unlucky, with negative equity and unsellable property). This of course is a universal feature of markets, namely that they are unpredictable, so it can be concluded straightaway that markets are disempowering to the extent that information about how they operate is never adequate. For many, perhaps most, owner occupiers, however, this disempowering quality of markets is obscured by the fact that for most of the time they are not thinking about moving home and are therefore not actively participating in the business of house 
purchase and sale.

For tenants, the situation is quite different. What they need most of all is information about the landlord's policies and practices, and explanations and justifications of these. They need regular and detailed information on what is happening in their home area, including reports on the performance of landlord's representatives and agents in the area. For secure tenants of local authorities and housing associations, empowerment through the provision of such appropriate information has been stimulated by legislation. For example, the Housing Act 1980 conferred on them rights to be informed about their landlord's allocation policy and to be consulted about proposed changes in management practice (except on rent levels). Later on, the Local Government and Housing Act 1989 section 167 required local authorities to report annually to their tenants in order to win approval for their schemes (for example under Estate Action, DoE, 1993). By various means, therefore, central government has contributed to the empowerment of social housing tenants through greater provision of appropriate information.

The contribution from landlords themselves has been more mixed. With regard to allocation policy, for example, a survey for the Chartered Institute of Housing found that typically local authorities had bureaucratic allocations systems which were geared more towards administrative convenience than assisting customers (Karn \& Stafford, 1990). In general, authorities did not attempt to explain or justify the policies which they had. With regard to information about management performance, there is no evidence that any authority supplied such information on a regular basis to all its tenants before the 1989 Act. Since 1990, however, some authorities have been stimulated to go well beyond their minimum statutory duties and provide a high quality of information which is of potential value to their tenants (Marsh et al., 1993). The decentralisation of housing services in many authorities from 1980 onwards has also often been associated with an improvement in the quality of communications with tenants (Mainwaring, 1988), although it is still generally the case that information available to tenants at estate level (as distinct from borough-wide information) is rarely adequate (Cairncross et al., 1989; Marsh et al., 1993). Overall, therefore, empowerment of residents through provision of appropriate information has not been an outstanding feature of local authority approaches (or of housing association approaches, for that matter), except when prodded into action by central government (or the Housing Corporation). The reasons for this have not been investigated, but it could be because of the inevitable costs involved in gathering and circulating such information and because of a desire on the part of local politicians and professionals to monopolise such information in order to protect their power.

Another aspect to the issue of empowerment through knowledge is the provision of training and education for tenants to perform specific roles and undertake new types of activity. The communication of information to tenants on its own is not likely to empower them to a significant degree. As Day \& Klein (1987) have noted, consumers do not generally use information about producer performance to press for changes in that performance or to influence practice in such a way as to increase consumer control. One reason for this could be that they lack the skills and understanding required to apply such information in the pursuit of their own empowerment. In recent years, official recognition of this 'skills gap' has led to the creation of a number of organisations, such as the Tenant Participation Advisory Service (TPAS), whose concern is, among other things, to encourage tenant empowerment by means of appropriate education and training. It has also led to the provision of special courses for tenants and tenant participation officers such as the Chartered Institute of Housing's Certificate in Tenant Participation. The government's own attitude to such tenant training, however, has been criticised as paternalistic and personalistic (Furbey et al., 1996), and this criticism raises an important issue about the nature of the knowledge and skills which tenants need in order to secure more effective control of their homes and their estates, rather than becoming simply more responsible and more respectable tenants. At this stage, one can perhaps only make a few tentative suggestions. For example, tenants may need training in how to budget at the estate level, they may need to understand better how the housing organisation works, they may need practice in organising themselves more effectively, they may need space and time to explore different possible options and opportunities for empowerment. Above all, tenants need encouragement and support in identifying their own training and education needs, so that they can set the agenda for themselves rather than following one already set by 
landlords or by government. As Baistow (1994/95, p. 37) has pointed out, the identification of one's own needs is an important part of the process of becoming empowered.

Returning to the typologies outlined earlier, it could be argued firstly that the limitations in empowerment from the communication of information by landlords and governments arise mainly from its 'top-down' character. As Symon \& Walker (1994) have pointed out, tenants may respond to such communications, but they are unlikely to be in a position to act upon them. Even if they have the necessary skills for action, they may choose not to do so, for various reasons (for example, they may calculate that the perceived costs of action outweigh the perceived benefits). Second, increased communication, even if the flow is only one-way, involves increased interaction, and therefore tends to result in increased interdependence. In this case, landlord and tenants in time will come to rely more on each other. On the other hand, however, if tenants choose to develop skills which enable them to manage for themselves (as part of a 'bottom-up' empowerment process), it is possible that at least some of them might grow to become less dependent on their landlord. In all, therefore, there are three possible courses which the process of empowerment could follow: passive absorption and acceptance of the knowledge supplied by their landlord and others; greater interaction leading to closer co-operation and mutual dependence between landlord and tenant; and greater independence and freedom of action leading to movement away from their landlord by individual tenants and tenant groups. In other words, tenants can choose options of loyalty, voice or exit, leading to 'conservative', 'reformist' or 'radical' outcomes. In this case, however, it should be pointed out that the reformist outcomes are not necessarily egalitarian. Increasing interdependence can occur within a paternalistic framework where the education and training of tenants serves to incorporate powerful tenants and tenant groups more effectively within the landlord's power structures. Such a situation is more accurately characterised as 'conservative reform'.

There is finally the issue of which tenants are empowered through the receipt of information, education and training. It seems likely that there will always be significant inequalities among tenants in how well they are informed on a range of matters affecting their everyday lives. Specific training courses for tenants could have the effect of cultivating elites who could dominate the selection of different collective tenant strategies. On the other hand, however, if such tenants remain in close contact with their grass roots, they could act as catalysts for the diffusion of a more universal and democratic tenant education.

Empowerment through Statute

Conferring rights on residents through legislation is potentially much more effective for empowerment purposes than the provision of information or education. The force of civil law is a uniquely strong institutional support for those seeking greater control over their lives. Owner occupiers already enjoy property rights which traditionally have been jealously guarded by the English legal system, although eroded to some extent by public health and planning legislation. At the present time, apart from certain relaxations of planning restrictions, there are no 'top-down' processes in motion which might involve an extension or enhancement of the existing rights of owner occupiers, let alone the conferral of new ones. Possible candidates for such new rights include rights for protection of the home owner 's equity, a right to sell (for example to a local authority), and rights to a safe and pollution-free environment. The adoption of such rights could be considerably empowering for poorer home owners in particular. Under its current legislative proposals, however, the government is planning to abolish mandatory house renovation grants, which effectively gave owner occupiers a right to have their homes made $₫ \mathrm{t}$ for their habitation. Current trends, therefore, under the guise of 'deregulation' are moving in the direction of the disempowering of owner occupiers.

For tenants, who lack the property rights of owner occupiers, a complex array of rights has developed over the years. From 1915 onwards, private tenants had their rents protected by law against increases (so-called 'controlled rents'), but interestingly this has always been seen as a disempowering of private landlords rather than an empowering of private tenants. The lower rents which resulted from such protection may have allowed private tenants to gain greater control over other aspects of their lives (because they had more money to spend on other things), but it did not necessarily give them any greater control over their housing (for example, it may have made it more difficult for them to get the landlord to carry out repairs). Moreover, the introduction of controlled rents created an incentive to landlords to evict old tenants in favour of new tenants 
who would pay higher rents, so the government had to provide a measure of security of tenure in order to protect tenants against this. Security of tenure, therefore, although clearly empowering of tenants (enabling stability of residence and an insurance against homelessness), was seen more as a means of protection against abuse than a new kind of civil right. Similarly with 'regulated rents' from 1965 onwards, the extent to which such legislation really empowered private tenants is questionable, except only in the sense of a protection against eviction (although it also conferred limited rights of succession to a tenancy). Since 1989, with the extension of the assured tenancy regime to all private sector tenancies, even this protection has been significantly reduced (for example in the case of shorthold tenancies where security is reduced to as little as six months). The result is that private tenants have now become less powerful than they have been at any time since 1915.

For public sector tenants, the watershed in terms of statutory rights was the Housing Act 1980. That Act gave local authority and housing association tenants extensive rights of security of tenure, rights to sublet and take in lodgers, rights of succession, and rights to carry out alterations to the property, as well as the Right to Buy and consultation rights which have already been discussed above. Clearly, this constituted a significant empowering of public sector tenants who now became 'secure tenants'. In practice, however, the Right to Buy has tended to overshadow all the other rights, with the result that empowerment has been seen largely in terms of the ability to exit from the tenure rather than in terms of increasing the freedom of manoeuvre within the tenure. Through the 1980s and into the 1990s, in spite of some 'reformist' examples, 'radical' approaches have tended to dominate, and one consequence of this has been that those remaining as secure tenants have not been significantly empowered by the 1980 Act changes.

A second major change for public sector tenants came with the Housing Act 1988. Whereas the 1980 Act granted exclusively individual rights to tenants, the 1988 Act introduced (albeit indirectly) a new collective right for local authority tenants to trigger their transfer to another landlord (the so-called Tenants' Choice), and also removed the 1980 rights for new housing association tenants (although to some extent these rights were restored through the Housing Corporation's Tenants' Guarantee). After 1988, therefore, the paths of local authorities and housing associations diverged, with council tenants becoming more powerful and housing association tenants suffering a disempowerment akin to that experienced by private tenants. Council tenants made little use in an explicit sense of the Tenants' Choice provisions, with a reported total of only 981 homes in England being transferred (Bright, 1995), but the mere existence of the legislation may have had an empowering effect, even if in practice the rights under the legislation (which was finally repealed by the Housing Act 1996) were rarely exercised. For example, it has been said that following the publication of the government's plans for Tenants' Choice in 1987 (DoE, 1987), hitherto arrogant and insensitive landlords began "desperately either to placate the tenants with belated promises of participation and improved services, or to offload their housing stock completely" (Birchall, 1992, p. 186). In response to the Tenants' Choice legislation, therefore, many local authorities sought to involve tenants more in the improvement of services, and such involvement inevitably carries with it a certain degree of empowerment. Those local authorities who aimed to dispose of their stock rather than improve their services also needed to ballot their tenants before they could proceed, and this again must have had a certain empowering effect on the tenants concerned. Although the extent of such empowerment is difficult to quantify, the key point is that as a result of the 1988 Act local authority tenants could collectively choose whether or not to stay with the local authority, and this was a uniquely powerful right. In practice, very few tenants' groups were ever likely to exercise such a right, not only because use of the Tenants' Choice provisions was found to be extremely cumbersome and time-consuming, but because the vast majority of tenants' groups probably prefer to sort matters out with their current landlord. Nevertheless, the choice not to exercise this right could be said to have been conditional upon the local authority's continuing good performance or good intentions, and this indicates that the collective power of council tenants in relation to their landlord was increased. The repeal of the Tenants' Choice provisions by the $1996 \mathrm{Act}$, therefore, clearly marks a significant disempowerment of council tenants.

Since 1988 the main new right to be introduced has been the Right to Manage for council tenants under section 132 of the Leasehold Reform, Housing and Urban Development Act 1993, although in its last year of office the Conservative 
Government re-introduced a limited Right to Buy for housing association tenants. The Right to Manage is clearly less empowering than Tenants' Choice, because it does not amount to a right to exit from local authority ownership. Nevertheless, until its repeal it was conceivable that the exercise of the Right to Manage by a tenants' group could lead on to a Tenants' Choice application. In any event, the Right to Manage appears to represent a valuable new option for those tenants who want more control over the housing services delivered to them and who want to remain as local authority tenants. In practice, however, it is difficult to see how a management agreement can be reached without good will and substantive cooperation on the landlord side, so legislation designed to support tenants' groups in the face of hostile authorities seems inappropriate. As with the Tenants' Choice provisions, the legislation seems to assume an adversarial approach, and this is an approach which few tenants' groups would be prepared to risk in the face of a local authority who remains much more powerful than they are (even with government funding and administrative assistance). It can be concluded, therefore, that the effects of the Right to Manage will be negligible compared with the effects of exit rights (Right to Buy and Tenants' Choice), and consequently the empowerment of tenants achieved by this right will be fairly minimal (although as with Tenants' Choice there may be unquantified, and possibly unquantifiable, indirect effects in terms of changing landlord attitudes and culture).

What sorts of rights apart from rights to change the tenure of one's home (which are not, in any case, enjoyed by private tenants) would be really empowering for tenants? Probably the most relevant would be rights to require specific performance of an agreed standard across the whole range of landlord services, rights to determine the form and content of any agreement on an equal basis with their landlord, and rights to appropriate levels and types of resourcing for 'bottom-up' empowerment processes. Also worth mentioning, pace Birchall (1992, p.165), are rights to negotiation or bargaining over important decisions, and rights to change their relationship with their landlord by developing various types of joint or self-management. Some landlords have already moved in the directions implied by such rights, and these moves are considered below.

Empowerment through Resourcing

As with empowerment through knowledge, the empowerment of tenants through the provision of appropriate resources has been considerably facilitated since 1986 by legislation. Specifically, Section 16 of the Housing and Planning Act 1986 provided for direct government subsidy towards setting up a tenant management organisation (TMO). For housing association tenants, further funding for similar purposes has been available from the Housing Corporation under Section 87 of the Housing Associations Act 1985 (Dean, 1992).

Apart from state subsidy, many landlords have provided various forms of assistance to tenants' groups such as the use of local offices and office machinery for meetings and newsletters and the provision of training, and some have appointed specialist tenant participation officers with an explicit brief to encourage 'bottom-up' processes of tenant empowerment. There seems little doubt that the resourcing of tenants' groups is increasing, but the effects of this increase in resources have not yet been properly evaluated. It could be argued that for empowerment purposes tenants themselves ought to be able to choose how they are resourced. At the moment, however, the balance of resourcing is tipped in favour of the development of TMOs because of the bias inherent in government funding.

There is another sense in which council tenants in particular have been disempowered, through the squeeze on local authority housing capital and revenue expenditure. There is some debate, however, over the extent to which council tenants controlled housing capital programmes and housing revenue accounts in the first place. Certainly, many Labour-controlled authorities in particular operated low-rent, low-spend policies over long periods in the belief that this was what tenants wanted, but hard evidence to support such beliefs is surprisingly lacking. In general, tenants were simply not consulted on such issues, and were probably not aware of the financial issues involved or of the resourcing choices which could be made. Now, to the extent that they are more consulted and better informed, they are likely to be more aware of how limited is the influence which they can have on key housing capital and revenue decisions.

Resourcing for tenants is therefore empowering, but only if the tenants have some say in determining how those resources are to be used. 'Top-down' processes, however, do not tend to be very good at achieving this. What is 
mainly required are forms of mediation between landlord and tenant which will ensure that resources supplied from the top are applied as effectively as possible at the bottom. There is a need for intermediaries, such as 'tenants' friends', who can explore different possible options with tenants and advise them accordingly. In practice, however, such intermediaries tend to be employed to follow an agenda already set by others, not by the tenants, and this agenda can be quite prescriptive, for example to develop tenant management organisations or to develop consultation arrangements only. For empowerment, what should happen is the tenants are assisted to de $®$ ne their own resourcing needs and aspirations for themselves, and then advised as to how best to proceed on the basis of the resources which are likely to be available. Because this is a continuing requirement for tenants and not a one-off situation, there is clearly a role for permanent mediators, such as tenant participation officers, who should have a wide-ranging brief to ensure that resources are used to maximum empowerment effect.

Resourcing for tenant empowerment is too important an issue to be left in the hands of specialist intermediaries. Housing management staff, especially in local offices, need to be deeply involved in order to achieve continual improvement in the understanding of what is practicable and realistic. Housing officers themselves can act as mediators between their landlord as their employer and their tenants as their customers, so they have a potentially significant contribution to make towards tenant empowerment. They too, however, need to be empowered in order for their contribution to be effective. At present, their skills and achievements go widely unrecognised within their organisations as well as in society more generally, and this situation has been contrasted unfavourably with that which exists in other countries such as Denmark (Aldbourne Associates, 1994), where the quality of public sector housing management appears to be higher. The presence of better resourced and higher paid front-line staff, especially residential staff, could have major implications for tenant empowerment, if accompanied by appropriate changes in organisational culture.

Another way of ensuring that tenants have greater control over their resourcing is by introducing new forms of democratic arrangement for this purpose.

For some years, a small number of local authorities, in particular Sheffield, have levied an extra charge on their tenants in order to finance tenant activities and organisation. On the whole, however, these levies have been imposed on the tenants concerned 'for their own good', that is paternalistically, and have not been under the tenants' own control. It is interesting to report, then, that the London Borough of Greenwich recently received support from its tenants for a proposal to bring the money which funds their organisations under direct democratic control (Inside Housing, 24.11.95). The services so funded include grants to tenants' associations, support workers and a resource and information centre. The fund, amounting to $15 \mathrm{p}$ per tenant, is controlled by a committee representative of all tenants. Such extensions of democracy are clearly empowering of tenants, but they are subject to the limitations inherent in democracy more generally (Somerville \& Steele, 1995b), and need to be supplemented by democratic arrangements at a more local and more accessible level. They also still depend for their success on the existence of appropriate forms of mediation at the local level (or levels) and at the organisational level.

What about resourcing for owner occupiers? This seems a strange question to ask because for them their home is a crucial resource in itself. However, there do exist a number of agencies such as Care and Repair which are dedicated to helping home owners, especially those who are elderly and frail, with the management, maintenance and improvement of their homes. There is a large unmet need for such agency services to enable owner occupiers to stay put in their own homes. The technical, legal and financial advice available through such agencies could also be of value to owner occupiers more generally. Empowerment through Agreement and Power Transfer The powerful effect of legislation raises issues about how much empowerment can really be achieved without legislative change. The general answer is probably quite a lot, but without legislation the political will for empowerment tends to be weak or non-existent. The clearest expression of such will is through processes whereby a landlord attempts either to forge new partnerships with its tenants or to transfer specific decision-making functions to tenant bodies. The latter involves the creation of tenant management organisations such as tenant management co-operatives (TMCs) or estate management boards (EMBs). The former involves semi-contractual or quasi-contractual arrangements such as estate agreements or bilateral (or possibly multilateral) covenants (Somerville \& Steele, 
1995a).

The contribution of tenant management organisations to tenant empowerment has recently been evaluated for the Department of the Environment by Price Waterhouse (DoE, 1995). They looked at three types of TMOs, which can be distinguished according to the extent of decision-making responsibility transferred. First, par-value co-operatives (PVCs), where housing association tenants collectively own or lease and manage the property but have no individual financial stake in the equity; second, TMCs, where local authority tenants have taken over responsibility for some housing management functions such as repairs and lettings; and third, EMBs, where some housing management functions are delegated to a board whose majority is elected by the tenants. They found that the most effective TMOs were those whose members had greatest control over their housing management, finances and environment, that is PVCs were most effective, TMCs were very successful but not as effective as PVCs, and EMBs were least effective. Effectiveness was measured in terms of the responsiveness and quality of repairs, the turn round times on reletting property, and the level of rent arrears in relation to the cost of service provision, but also in terms of levels of resident satisfaction, the existence of community spirit, the extent of crime and vandalism, and the acquisition of skills and experience relevant for employment. The research therefore suggests that degree of managerial effectiveness (which itself has implications for tenant empowerment) may be related to degree of tenant empowerment through transfer of decision-making responsibilities. This suggestion, however, needs to be treated with some caution. One problem is that of the size of the management unit. Based on Swedish experience, it can be argued that estates with well over 1000 properties as occurs with many EMBs are likely to be too large for the tenants collectively to exert control in any meaningful sense (Somerville \& Steele, 1995b). In residential areas of this size, the gap between board members and the bulk of residents is such that it cannot be said that the latter really have control over the housing in which they live. It is possible, therefore, that smaller EMBs, with perhaps 200 or so properties, which would be more empowering of residents, might also be more effective than larger ones, and perhaps almost as effective as TMCs. It cannot be definitely concluded that degree of empowerment depends upon the type of tenant participation arrangement, because so much hinges on the conditions which exist in any particular residential area, for example a higher level of resident involvement and strong community institutions will tend to lead to the formation of a co-operative but will also tend to result in more effective management anyway, whether a co-operative is formed or not. For this reason alone, a better management performance from co-operatives is only to be expected.

There is a degree of complexity here, which is only beginning to be explored. The typologies developed earlier in this paper can help to unravel this complexity. To some extent, for example, it results from 'top-down' processes of power delegation and decentralisation meeting 'bottom-up' processes of tenant organisation, assertiveness and communal action. The situation is inherently dynamic and volatile, and the outcomes at present are difficult to predict. Naturally, the increasing range of options being made available to tenants makes outcomes increasingly unpredictable. Nevertheless, outcomes can be classified in terms of their 'conservative', 'reforming' or 'radical' character, and to this extent the processes themselves can be understood. For example, TMCs will be more 'radical' than EMBs only insofar as they involve the transfer of more decisionmaking functions. In practice, however, the transfer of functions tends to be similar in both types of arrangement, so in similar-sized TMC and EMBs the degree of 'top-down' tenant empowerment achieved should be similar. If this argument is correct, then the greater level of tenant empowerment observed in TMCs can be attributed to 'bottom-up' processes, that is it has been achieved by the tenants' own collective efforts and organisation.

To take another example, par-value co-ops (PVCs) are more 'radical' than TMCs because they involve a transfer of ownership, not just of management. As has already been noted in relation to the Right to Buy, transfer of ownership is a particularly radical measure, which leads to a qualitatively new level of empowerment. It is to be expected, therefore, that, other things being equal, PVCs are likely to be more effective than TMCs, and the Price Waterhouse research confirms this.

Support for the above argument can be found in the theoretical and empirical literature on corporatism and on implementation theory. Lewis (1990), for example, argues that "effective action by organisations . . . requires learning 
capacity" (p. 80), that is the ability to acquire skills on a collective basis which will ensure that the organisations achieve their objectives. From this point of view, new policy initiatives such as statutory rights or decentralisation represent opportunities of varying extents for organisations such as tenants' groups to broaden and deepen their knowledge and skills. Taking advantage of such opportunities can then result in their empowerment, and the degree of such empowerment will tend to reflect the size of opportunity offered. In a similar vein, Simmie (1990) has argued that consumer-oriented groups at local level can indeed be effective if they have the necessary resources, education, political skills, and sheer persistence. Simmie also points out that sympathetic organisations at central government level can also make a huge difference (Simmie, 1990, p. 194). The general conclusion to be drawn from the literature is that the outcomes of the interaction between 'top-down' and 'bottom-up' processes will depend primarily on how the interaction is mediated, and this is the subject of a separate paper (Somerville \& Steele, 1996).

In general, the transfer of power to TMOs, whether they be PVCs, TMCs or EMBs, represents a radical approach to tenant empowerment. Potentially, this approach is highly effective, but it suffers from unpredictability, and tends to 'lock' tenants into one particular type of tenant participation arrangement, with little freedom to change to a different type if they so wish. Moreover, there is a widespread reluctance among tenants generally to take on the burdens of management responsibility. For these reasons, freely negotiated agreements between landlords and tenants' groups have been suggested as an alternative. Such agreements represent a less radical approach to tenant empowerment, but there is a greater potential for the landlord's power to be used to support tenants rather than leaving them to fend for themselves as can happen with the more radical approaches. The main point, however, is that tenants should be able to choose freely whether to move closer to or further away from their landlord, whether to be more (inter)dependent or more independent. Empowerment does not necessarily involve following the 'radical' path, but being in a position genuinely to decide whether to follow the 'radical' path or not. At present, most tenants are not in such a position because they are not aware of the choices involved and their landlords are not committed to giving them such freedom. The potential for new forms of partnership between landlords and their tenants, involving increasing interdependence, is enormous but relatively unexplored. We are, after all, only just beginning to understand the empowerment which can be produced through the operation of interorganisational and policy networks (Elander, 1995; Reid, 1995; Reid \& Iqbal, 1995). For the time being, therefore, we have to rely on small-scale research such as that into estate agreements in England (Steele et al., 1995) and bilateral covenants in the Netherlands (Pott \& Smeets, 1994). Such research indicates that landlords are as likely to be committed to partnerships with their tenants as they are to following more radical approaches, that is only in exceptional cases. Even some of the few landlords who have actually developed estate agreements do not see them as particularly empowering of tenants, but only as a means towards more effective consultation and more structured and purposeful performance organisation and monitoring.

An estate agreement empowers tenants primarily through ensuring the accountability of their landlord. The agreement specifies estate priorities and performance targets for the coming year, and the landlord's activities can then be evaluated against these priorities and targets. The empowerment is limited because there is no right of redress or right to compensation in the event of landlord default on the terms of the agreement, but such rights could be developed in time. Also, in the absence of a budget dedicated to the estate, the tenants have little real financial control, but again estate budgeting could be developed if there were the political will to do so. Overall, with a few notable exceptions such as Camden, Manchester and York, there is some doubt as to whether landlords are seriously committed to empowering their tenants through forms of partnership such as estate agreements. Such a conclusion prompts the question of whether perhaps landlords should be compelled by legislation to develop such agreements, but such legislation would be open to the same criticisms as those levelled against the Right to Manage, namely the tenants depend for their empowerment upon their landlord's co-operation, and compulsion would have, and in some cases does have, precisely the opposite effect. What is needed instead is more extensive and substantial support for tenant organisation and education, and not just in the public sector either. In general, returning to the debates from the early part of this paper, it can be 
said that rights of exit and voice are empowering partly, or even mainly, because they promote the transfer of power to those on whom the rights are conferred. For tenants, however, such rights need to be supplemented by willingness on the part of their landlords to work together with them on a more equal basis and to provide them with the information they require in order to make free and rational choices. Finally, in order to ensure that the transfer of power is not monopolised by an elite group of tenants, it is important that appropriate arrangements are made for democratic tenant representation and for the diffusion of the transferred power to all minorities within the tenant body.

\section{Evaluation of the Empowerment Typology}

The consideration of the evidence on resident participation in the previous section enables a preliminary assessment to be made of the strengths and weaknesses of the model outlined in the third section. In this section, therefore, each classificatory criterion is briefly examined in turn, and a verdict is passed on the typology overall.

Direction of action. The classification of empowerment processes in terms of the direction of empowerment action (either from the top downwards or from the bottom upwards) has been found to be particularly useful for making sense of a variety of activities affecting landlord-tenant relations, especially in relation to legislation and the uses to which legislation has been put, and also in relation to arrangements made for power transfer and power sharing between landlord and tenants. However, the patterns of interaction between 'top-down' and 'bottomup' processes remain substantially unclear, and require further investigation in a variety of contexts in order for the utility of the model to be fully demonstrated. Institutional change. The distinction between 'conservative', 'radical' and 'reformist' empowerment has been found to be useful for making sense of policy processes at national and local levels. 'Conservative' processes leave the current balance of power relations essentially unchanged, 'reformist' processes retain the core power relationship (in this case, the landlord-tenant relation) but tend to place that relationship on a more equal basis, while 'radical' processes involve a decisive break from the core power relationship. As with the criterion of direction of action, however, this classification may turn out to be too crude to do justice to the complexity of institutional change wrought by empowerment processes. For example, 'conservative' processes are in fact compatible with substantial changes in the nature of power relations in a specific social context (for example, local government reorganisation or departmental restructuring). The balance of power between landlord and tenant may remain the same even though the character of the landlord (and perhaps also of the tenants) has changed drastically. Or again, the process may be substantially empowering of tenants, but it may be empowering of landlords also to the same degree, so that the overall balance of power is unaffected.

Dependency effect. This criterion has been found to be less useful than those of direction of action and institutional change. Nevertheless, from the residents' point of view, it is important to distinguish between those processes which will tend to increase their dependence upon landlords, local authorities and other sources of power, and those which will tend to give them more freedom of manoeuvre in relation to these 'powers-that-be'. Admittedly, however, this is not a distinction which is always easy to draw in practice. Perhaps the key development required here is the education and resourcing of the residents concerned, so that they are aware of all the implications and can decide for themselves the degree of dependence or independence which is most suitable for them. Beneficiaries. In relation to formal legal and political processes in particular, it has been found important to ask who are the main beneficiaries. For example, the distinction between individual and collective rights conferred by legislation has been argued to be a useful one (Birchall, 1992, p. 165), and the issue has also been raised as to whether certain arrangements empower residents as a whole, or only small (elected or unelected) cliques. It has not been established, however, whether different types of beneficiary are actually produced by characteristic types of empowerment process. For example, is there a particular way of policymaking and implementation which is more likely to bene ${ }^{\circledR} t$ the great mass of residents rather than a privileged few? Answering such a question should lead into a more complex and detailed discussion of the mechanisms and style of empowerment in specific local contexts. Again, we would expect the education and resourcing of residents to figure prominently in such discussion.

Overall, therefore, the typology has been demonstrated to have a certain utility, but it is relatively undeveloped. Further research is required to test certain elements of it, and to fine-tune much of the provisional classification. It could be 
argued that it has potential, but much needs to be done in order to realise this potential, and in the meantime the typology looks vulnerable to criticism.

\section{Conclusion: The Empowerment of Communities}

This paper has been largely, though not exclusively, concerned with the empowerment of tenant collectives. Typologies of empowerment processes have been developed, and means of empowerment such as information, legislation, resources and transfer of functions have been considered and evaluated in the light of these typologies. The argument in the paper has a number of implications for community development and the changing role of housing management, which are perhaps worth looking at more closely.

First of all, by whatever means the empowerment takes place, the key question is whether it helps to place residents in a position where they can choose their own way forward: following a 'radical', 'egalitarian' or 'conservative' path, becoming more independent or more interdependent, and selecting for themselves their own participation arrangement and their own individual level of participation within that arrangement. They therefore need knowledge and skills in order to make an informed choice, rights to secure access to such knowledge and skills and to redress any unequal balance of power between landlord and tenant (for example, rights to switch tenure, rights to resourcing, rights to minimum service standards, and rights to negotiate with the landlord), control over an appropriate level of resources for their own organisation, and suitable agreements with any landlords or other service providers operating in their area concerning management and other matters affecting the area.

As noted in particular in relation to the research for the DoE on TMOs, the empowerment of residents is worth pursuing not only for its own sake, but for the benefits which it can bring for community health and safety and well-being. As mentioned at the beginning of the paper, in practice there may not be any clear dividing line between housing and non-housing aspects of residential empowerment. Consequently, there is a need for intermediaries such as 'tenants' friends', tenant participation officers, and local housing officers, to be more 'generic' in their skills and knowledge, in order to be more effective in the mediation of such empowerment. This does not mean that their role should be merged with that of community workers (Smith, 1992), but only that the community dimension of housing work needs to be more widely recognised, and the importance of housing work for community development more widely appreciated. Local housing offices can provide foci for community-building and community-sustaining activities (Power, 1984), and the estate-based multiagency collaboration which results can lead to the establishment of 'community institutions' (Foster \& Hope, 1993, p. 14) such as parent-and-toddler groups, preschool playgroups, youth clubs, and so on. The empowerment of residents by whatever means will tend to encourage a wider empowerment of the communities in which those residents live, given the existence of appropriate forms of institutional mediation (and what is appropriate will depend upon a number of factors, not least the type of participation arrangement chosen by the residents). In this way, most housing and social problems are actually capable of satisfactory solution, although more than empowerment is required to achieve this. What is needed in addition, and which is sadly lacking in contemporary Britain, is the political will at national and at local level.

The emphasis in this paper on the empowerment of tenant collectives should not be taken to imply that the empowerment of tenants is more important than the empowerment of owner occupiers. Rather, it reflects the greater volume of literature concerning tenant involvement as well as the fact that ownership itself represents a significant level of empowerment. This should perhaps not be overstated in view of the perennially expressed concern for so-called 'marginal' home owners (for the most recent evidence on this, see Kempson, 1994), but nevertheless the bulk of evidence suggests that disempowerment for owner occupiers arises primarily from lack of income or stable employment and from the vicissitudes of the housing market. Such problems need to be tackled through economic, employment and fiscal policy, and perhaps new forms of housing market regulation, but a discussion of such measures is beyond the scope of this paper. There is an important issue here, because, as Harrison (1995) has emphasised, empowerment should not be seen as applying only to the disadvantaged (or socially excluded or whatever) but to all of us who find ourselves outside the ruling elites of capitalist society.

A rather different point concerns the implications of the arguments in this paper for the theoretical debate on tenant participation and for future research in this area. In Somerville \& Steele (1995a), a typology of institutional arrangements 
for tenant participation was presented, and each type of arrangement was assessed in terms of its potential for changing the balance of power between landlord and tenant. This typology must now be reviewed in the light of the arguments in this paper relating to different modes of institutional change (conservative, reformist, or radical). Specifically, the distinction made in the earlier paper between low, medium and high degrees of change in the balance of power now appears too crude, and should therefore be replaced by the (only slightly less crude) conservative/reformist/radical trio. The effect of this change for the different types of institutional arrangement is summarised in Table 2.

Table 2. Types of empowerment produced by different

types of tenant participation arrangement

Type of arrangement Type of empowerment

Internal market (e.g. CCT) Conservative

Landlord-tenant partnerships Reformist

Tenant-controlled management Radical

Drawing all these points together, the following important conclusions can be made:

- Residents can be empowered most radically by conferring on them specific rights to make decisions over their own lives, and by specific transfers of ownership, control and resources. These changes, however, should be seen not so much as empowering in themselves as presenting opportunities for residents to achieve empowerment for themselves. Strictly speaking, empowerment is not to be equated with owning or controlling or managing as such, but rather with the gaining of the freedom to choose whether to own or not to own, to control or not to control, to manage or not to manage. Such freedom of choice comes only with the acquisition of relevant knowledge and skills, in addition to appropriate statutory rights and redistribution arrangements.

- By and large, politicians at national and local levels are not primarily interested in resident empowerment, and tend to follow their own, quite separate, agendas. For example, the Conservative government tended to empower tenants only with a view to weakening local authorities (Somerville \& Steele, 1996), while local authorities themselves have generally wanted to retain their monopoly position and avoid any form of power sharing with resident groups. All too often, national and local policy has tended to favour the cultivation of an elite of well-informed, skilled residents, who will act on behalf of all the other inhabitants of an area. This is, however, precisely the model of representative democracy which gives rise to the problem of disempowerment in the first place. The irony is that it is only the elites at national and local level who do not need empowerment, so the creation of yet more elites (albeit at lower levels) cannot possibly bring about a solution to the disempowerment problem. What is required instead is more broadly based and more inclusive education and training for empowerment, with more effective systems for delivering accountability and democratic control.

- Improved systems for promoting empowerment at local level can be facilitated through appropriate forms of mediation. For example, tenant participation officers and housing estate officers could well be capable of mediating the resourcing of tenants in such a way as to empower the recipients. For this to work, however, the officers themselves would need to be empowered, and once again the political elites are not willing to do this.

- Democratic control of resourcing by tenants themselves represents a significant level of empowerment. In practice, however, national and local politicians have been reluctant to allow transfer of ownership to democratically-run tenant bodies (Thamesmead and Walterton \& Elgin Community Homes are the only major examples of such transfers in England, and both occurred in exceptional circumstances). This situation may change, however, following the Government's decision to allow tenant-controlled local housing companies. - The creation of effective systems for empowerment at local level has implications going way beyond the considerations of housing policy. In a separate paper (Somerville \& Steele, 1996), I have argued that "in certain circumstances residence can form the basis for a more holistic mediation of social interaction". For example, local housing offices could operate as 'one-stop shops' for all services to the local area, and these offices could be controlled by tenant majority boards, or could be run by partnerships between tenants and their landlord. Essentially, tenants' groups could work together with local housing management to agree on social priorities for the area and ways in which these priorities could be translated into action on the ground. By this means, the focus on housing issues could be extended to cover economic and social issues more generally. 
- To some extent the typology can be used to explain differences in the effectiveness of different power transfer arrangements. For example, transfers of ownership tend to be more effective or more empowering because they involve 'radical' institutional change and increasing independence for residents, and typically bene ${ }^{\circledR} \mathrm{t}$ the resident body as a whole. In contrast, transfers of management, for example, are less 'radical', they may be more beneficial only for certain sections of the tenant body, and the tenants are liable to continuing dependence on the landlord as property owner. This conclusion, however, should not be allowed to detract from the point made above that the crucial issue for empowerment concerns the degree of freedom which residents can exercise in relation to whether or not to enter into any particular power transfer arrangement.

- One implication of the different possible and intended outcomes of empowerment processes is that the politics of residence and community must be irreducibly different from politics as traditionally understood. The most stark illustration of this is that empowering processes which are described as 'conservative' in the sense of making no substantial institutional change can actually be more empowering than 'radical' processes which alter completely the nature of current institutional arrangements. For example, a local authority which delivers a high quality of service to its tenants will tend to be more empowering of those tenants than one which transfers its management or housing stock to its tenants and simply leaves them to get on with it. On reflection, however, this situation is perhaps not so far removed from a national politics where a working-class movement attempts to 'conserve' what little power it has in the face of 'radical' Tory onslaughts designed to undermine its very existence. In both cases, what is at issue is the defence, and if possible enhancement, of the power bases of ordinary people (that is, those who find themselves outside the national and local decision-making circles). Acknowledgements

I am grateful for the comments from Bo Bengtsson, Malcolm Harrison and two anonymous referees on earlier drafts of this paper.

\section{References}

Aldbourne Associates (1994) Can Housing Managers Learn to Dance? (York, Joseph Rowntree Foundation)

Baistow, K. (1994/95) Liberation and regulation? Some paradoxes of empowerment, Critical Social Policy, 42(3), pp. $34-46$

Barnes, B. (1988) The Nature of Power (Cambridge, Polity Press)

Birchall, J. (1992) Council tenants: sovereign consumers or pawns in the game? in: J. Birchall (Ed.)

Housing Policy in the 1990s (London, Routledge)

Bright, J. (1995) A short history of failure, Inside Housing, 22 September, pp. $14-15$.

Cairncross, L., Clapham, D. \& Goodlad, R. (1989) Tenant Participation in Housing Management (London, Chartered Institute of Housing/Tenant Participation Advisory Service).

Cairncross, L. Clapham, C. \& Goodlad, R. (1994) Tenant participation and tenant power in British council housing, Public Administration, 72, pp. $177-200$.

Clegg, S. (1989) Frameworks of Power (London, Sage).

Day, P. \& Klein, R. (1987) Accountabilities: Five Public Services (London, Tavistock).

Dean, R. (1992) Independent Funding for Tenants (Coventry, Institute of Housing).

DoE (1987) Housing: The Government's Proposals. Cmnd 214 (London, HMSO).

DoE (1993) Estate Action: New Life for Local Authority Estates (London, HMSO).

DoE (1995) Tenants in Control: An Evaluation of Tenant-Led Housing Management Organisations (London, HMSO).

Dwelly, T. (1996) Living in the Future: 24 Sustainable Development Ideas from the UK (Coventry, UK National Council for Habitat II).

Elander, I. (1995) Policy networks and housing regeneration in England and Sweden, Urban Studies, 32(6), pp. 913-934.

Fordham, G. (1995) Made to Last: Creating Sustainable Neighbourhoods and Estate Regeneration (York, Joseph Rowntree Foundation).

Foster, J. \& Hope, T. (1993) Housing, Community and Crime: The Impact of the Priority Estates Project. Home Office Research Study No. 131 (London, HMSO).

Foucault, M. (1980) Power/Knowledge: Selected Interviews and Other Writings C. Gordon (Ed.) (Brighton, Harvester Press).

Furbey, R., Wishart, B. \& Grayson, J. (1996) Training for tenants: 'Citizens' and the enterprise culture, Housing Studies, 11(2), pp. 251- 269

Harrison, M.L. (1995) Housing, 'Race', Social Policy and Empowerment (Aldershot, Avebury). Inside Housing (1995) Vote for democracy, 12(46), p. 7.

Karn, V. \& Stafford, B. (1990) Housing Allocations: Report of a Survey of Local Authorities in England and Wales (Coventry, Chartered Institute of Housing)

Kempson, E. (1994) A Foot on the Ladder: A Study of Households on the Margins of Owning and Renting (London, HMSO)

Lewis, N. (1990) Corporatism and accountability: The democratic dilemma, in: C. Crouch \& R. Dore (Eds) Corporatism and Accountability: Organised Interest s in British Public Life (Oxford, Clarendon Press).

Lukes, S. (1974) Power: A Radical View (London, Macmillan)

Mainwaring, R. (1988) The Walsall Experience: A Study of the Decentralisation of Walsall's Housing Service (London, HMSO).

Marsh, A., Niner, P. \& Symon, P. (1993) An Evaluation of the First Year Experience of the Local Authority 
Reports to Tenants Regime (London, HMSO).

Mathey, K. (Ed.) (1992) Beyond Self-Help Housing (London, Mansell Publishing).

Pott, M. \& Smeets, J. (1994) Privatisation regulated: consequences of privatisation for the social relations between local authorities, housing associations and inhabitants. Paper presented to European Network

for Housing Research conference at the University of Glasgow, 29 August- 2 September.

Power, A. (1984) Local Housing Management (London, Priority Estates Project).

Reid, B. (1995) Interorganisational networks and the delivery of housing services, Housing Studies,

10(2), pp. 133-149.

Reid, B. \& Iqbal, B. (1995) Redefining housing practice: Interorganisational relationships and local housing networks. Paper presented to Housing Studies Association conference on 'The Governance of Housing' at the University of Edinburgh, 11-12 September.

Room, G. (1995) Poverty in Europe: competing paradigms of analysis, Policy and Politics, 23(2) pp. 103-113.

Sabatier, P. (1986) Top-down and bottom-up approaches to implementation research: A critical analysis and suggested synthesis, Journal of Public Policy, 6(1), pp. 21- 48.

Simmie, J. (1990) Corporation and planning, in: C. Crouch \& R. Dore (Eds) Corporatism and Accountability: Organised Interests in British Public Life (Oxford, Clarendon Press).

Smith, J. (1992) Community Development and Tenant Action (London, Community Development Foundation).

Somerville, P. \& Steele, A. (1995a) Making sense of tenant participation, Netherlands Journal of Housing and the Built Environment, 10(3), pp. $259-281$

Somerville, P. \& Steele, A. (1995b) Residential democracy. Paper presented to International Association of Housing Science conference on 'Excellence in Housing: Prospects and Challenges in the "Pacific" Century', Singapore, 25- 29 September.

Somerville, P. \& Steele, A. (1996) Housing policy implementation: The role of mediation, Scandinavian Housing and Planning Research, 13, pp. $147-162$.

Steele, A. Somerville, P. \& Galvin, G. (1995) Estate Agreements: A New Arrangement for Tenant Participation (Salford, University of Salford).

Stewart, J. \& Taylor, M. (1995) Empowerment and Estate Regeneration (Bristol, Policy Press). Symon, P. \& Walker, R.M. (1994) A consumer perspective on performance indicators: The local authority Reports to Tenants regimes in England and Wales, Environment and Planning C, 12 pp. 195- 216.

Turner, B.S. (1990) Outline of a theory of citizenship, Sociology, 24(2), pp. $189-217$.

Turner, J.F.C. (1982) Issues in self-help and self-managed housing, in: P.M. Ward (Ed.) Self-Help Housing: A Critique (London, Mansell Publishing).

Ward, C. (1976) Housing: An Anarchist Approach (London, Freedom Press).

Zimmerman, M. \& Rappaport, J. (1988) Citizen participation, perceived control and psychological empowerment, American Journal of Community Psychology, 16(5), pp. 725 - 750. 